\title{
Implementation and Commercialization of the Results of the "Multidisciplinary Mobile Computer Classroom Based on Raspberry Pi" Project
}

\author{
https://doi.org/10.3991/ijet.v15i13.14665 \\ Aizhan Zharkimbekova ${ }^{\bowtie}$, Ademi Ospanova, Kakim Sagindykov \\ L.N. Gumilyov Eurasian National University, Nur-Sultan, Kazakhstan \\ zharkimbekovaai@rambler.ru, aighan@mail.ru \\ Makhabbat Kokkoz \\ Karaganda State Technical University, Karaganda, Kazakhstan
}

\begin{abstract}
This paper describes the developed technology for using the Raspberry Pi microcomputer to teach practical skills on computer networks and operating systems. The paper presents a largely implemented project on an initiative basis, preceding the work on commercialization of the described results. In the present work a full detailed content of the steps for implementation and subsequent commercialization of the solutions presented in the project is given. There was assembled a prototype of the hardware-software device. There were developed individual training kits for distribution to students in the classroom. To study the disciplines "Computer Networks" and "Operating Systems", a methodological manual is being prepared for studying these disciplines using these training kits; the guidelines for operation of devices and components were developed. The work also prepared boot files with the predefined working environment for each discipline. These files include the needed operating systems, the needed pre-installed software, a customized user interface, the needed literature, a training manual, and methodological recommendations. In terms of commercialization, the calculations were carried out on the costs of organizing a computer class based on the Raspberry Pi: implementation of the developed technology; the effectiveness of its implementation was evaluated. A commercial plan was drawn up and calculations were made on the current date with the reference mainly to Kazakhstan; the trial design and layout of the packaging case, information stickers and cover (as well as layout) of the training manual were completed; industrial designs were developed in order to prepare the project for commercialization. The results are practically significant, when they were received, widespread methodology and development tools were used, they can be universally used, including in the field of education without any restrictions.
\end{abstract}

Keywords-Commercialization; computer networks; hardware-software device; operating systems; Raspberry Pi; training. 


\section{Introduction}

One of the weak points of vocational education in such areas as "Operating Systems" and "Computer Networks" is the problem of organizing practical classes due to their demand for hardware resources. The training course should effectively ensure the acquisition of sustainable demanded skills at the level sufficient in the modern professional field.

The computer classes of many education institutions are organized in such a way that the same operating system is installed on all the machines in the class, or several operating systems are installed on one computer. The computer network is, as a rule, configured, and its reconfiguration by students are not provided. The analysis of information of the computer laboratories, the hardware and software configuration of computers in the laboratories published on the websites of universities around the world, shows a similar practice of organizing computer classes. So, on the website of Stanford University, a schedule of employment of computer classes [1] is available, as well as a description of the computers in them. For example [2], it is a laboratory equipped with Apple iMac computers, or [3] it is a 24-hour training laboratory for computers with two Mac and Windows systems installed. The pages of [4] provide information of some laboratories at Massachusetts University of Technology; work [5] contains information of then computer labs at Harvard University. Well-organized communication in this area is at Carnegie Mellon University. Indeed, the class schedule is implemented in a convenient form (see work [6]). Works [7-8] are examples of descriptions of free access laboratories. It is noteworthy that many of them are equipped with a small number of machines with different operating systems (in work [7] there are 7 Mac-, 2 Linux-, 5 Windows-machines, in work [8] there are 3 Macand 2 Windows-machines). However, laboratories for scheduled classes are, as a rule, a collection of computers with the same operating system installed: for example, [910]. This is explained by the fact that the same class is used for conducting various disciplines, and a uniform working environment is necessary for teaching some of them. The exception is computers with free access. Section II.1 of this work identifies the reasons that impede implementation of full-fledged practical exercises in the computer networks and operating systems with access to tools and independent manipulations needed for obtaining sustainable practical skills. Briefly, these reasons, due to specifics of the disciplines, can be characterized by the absence of sufficient hardware and computing resources for the individual provision of students. At the same time, the use of conventional computers/monoblocks and equipment increases the requirement for floor space.

In the works covering this subject, two main aspects can be distinguished. The first group of works is dealing with studying the possibility of using various software in conducting practical classes in these disciplines. So, in work [11] the results of applying the Edmodo platform in teaching disciplines, including "Operating Systems", are presented. There is noted increasing the efficiency of assimilation. In work [12], in view of limitations indicated above, a method for studying operating systems using software tools is considered; in particular, a website is specified that imitates the Ubuntu operating system. In work [13] a solution to the problems of teaching the course 
"Computer Networks" at a university is described, which is associated with the same limitations that are outlined in this paper. As it is noted, positive results were achieved through the use of a specially developed cloud platform. In work [14] the necessity of using visual tools for better mastering this discipline and the difficulties associated with personal provision of network equipment are also noted. In this connection, network modeling software, network simulation programs, in particular, such popular software as Cisco Packet Tracer, are discussed in more detail there.

The second aspect of research in this area addresses the possibility of using additional or alternative equipment for organizing workshops in resource-intensive disciplines. And here, first of all, it is necessary to note a large role of single-board minicomputers such as Raspberry $\mathrm{Pi}$, as well as software and hardware systems such as Arduino. Since in most sources of the second group the results are based on the use of the Raspberry Pi, here is a brief description and examples of using this computer.

Raspberry Pi is a single-board computer based on the ARM processor that has long gained popularity. Its features are:

- A small form factor and weight, which gives good transportability and saves space both during storage and during operation

- Relatively cheap (the cost of the 3B+ model is $\$ 35$ )

- Technical characteristics that provide the ability to perform most educational tasks in these disciplines

- The presence of built-in interfaces and connectors for configuration with additional devices. Many Raspberry Pi models are equipped with interfaces RCA, HDMI, USB, MicroUSB, GPIO, they support Wi Fi and Bluetooth

- The ability to create or purchase modules and expansion cards that provide new paths for developers: boards with more powerful video and sound adapters; support for camcorders and other peripherals; boards with power supplies that provide portability of the device; Arduino-type expansion cards providing extensive design and robotics capabilities

- The availability of various, including "lightweight", operating systems loaded from the ISO image makes the device indispensable for educational, research, experimental purposes

- Being a full-fledged computer with support for many popular operating systems, Raspberry Pi allows creating diverse software

- The ability to almost instantly change the operating system. The computer storage is a micro SD memory card. Despite a lower fault tolerance compared to conventional hard drives, this feature is useful when there is a risk of failure of the operating system, and if it is necessary to quickly replace it by another

The latest versions are 3B+ and $4 \mathrm{~B}$ (4-core, RAM up to $4 \mathrm{~GB}$, built-in network card, $1000 \mathrm{Mbps}$ Ethernet, etc.). A more detailed description of the technical characteristics and some configurations of devices are available, for example, in $[15,16]$.

Raspberry Pi is dealt with by recent publications and editions with a large number of topics ranging from the creation of programmable devices based on the Raspberry Pi for various purposes to its use in programming, information security, robotics, and the Internet of things. So, in work [17] it is proposed to use clusters collected from 
microcomputer data to implement the data mining algorithms, which is a resourceintensive and at the same time popular IT industry. Here, using the examples of Apriori algorithm implementations and k-means clustering, a comparative analysis of clusters is given, on the basis of which the cluster efficiency based on Raspberry Pi is proved in some parameters. We note another work that describes implementation of a web server based on the Raspberry Pi with the ability to replicate and use it to conduct student surveys through their mobile devices [18]. Work [19] describes in detail the development of a prototype device based on the Raspberry Pi for transmitting sound through FM radio waves; as one of the applications, the possibility of training people with visual impairments is described. In work [20] a web application was developed using the Node.js platform for remote control of systems engineering and automation objects. In work [21] a wireless sensor network created on the basis of the Raspberry $\mathrm{Pi}$ and Arduino is described, the web development for displaying its work, and an example of its use is given. Work [22] presents the results of the operation of an optical measuring system created on the basis of the Raspberry Pi and the LED projector to restore the geometry of the parts. In work [23] a set of projects based on this microcomputer, suitable for development by schoolchildren, is given. Book publications also offer projects for children (see [23]). Works [24-27] are dealing with developments in the field of the Internet of things using various Raspberry Pi models. In works [28, 29] many applications of Raspberry Pi are described, including wireless projects based on the Raspberry Pi Zero W. In works [30-33] various projects with programming in Python are collected, including those on the Raspberry Pi Zero W. In works [34-37] the Raspberry $\mathrm{Pi}$ is being studied comprehensively, projects are being proposed, ways to expand the capabilities of the computer due to the available in a large number of hardware components, as well as their development are being considered.

One can note that there are other single-board microcomputers with similar hardware capabilities that also support various assemblies and configurations [38-40]. We turn to the consideration of works of the second direction: works in which the use of alternative hardware in the teaching of certain disciplines is proposed. The world experience of using Raspberry Pi microcomputers in the educational process is reflected in an extensive list of editions and book publications. So, in work [41] it is proposed to use Raspberry Pi for the purpose of teaching the programming languages $\mathrm{C} / \mathrm{C}++$, Java, a comparative analysis of the efficiency using conventional computers according to various criteria is given. We note here that, due to the availability of Unix-like operating systems for this microcomputer, GCC on computers can be said to be out of the box. By the way, the Raspberry Pi was developed to teach computer science and programming [42]. In work [43] a similar idea was expressed about the possible effectiveness of using single-board Raspberry Pi computers in teaching sections of the disciplines, which are often studied in theory for absence of suitable equipment. Note also that in work [44] some projects based on the Raspberry Pi were proposed, including the use of it in teaching. In work [45] the start of work at using the Raspberry Pi at the university for cybersecurity practice was announced. The practical studies presented in works $[46,47]$ are dealing with yet another area in software development and teaching, which requires significant hardware resources (computer 
park), on the one hand, and are associated with the routine work of organizing and setting up equipment and software, on the other hand. Work [46] is dealing with the problem of developing a computing cluster based on the Raspberry Pi for the purpose of teaching parallel programming; the process of cluster assembly is described. In addition, a step-by-step instruction is given on the configuration on the assembled cluster of the interface for distributed computing Open MPI, and setting up access via the ssh protocol. In work [47], among other things, an assessment was made of the effectiveness of devices assembled based on the Raspberry Pi. Note that the first work with a detailed description of the process of developing a computing cluster using Raspberry $\mathrm{Pi}$ is article [48] that was also published in the academic journal [49]. In work [50] students' projects are presented, developed as a part of studying the discipline "Operating Systems" and implemented on the Raspberry Pi. It is noted that the approach of using the Raspberry $\mathrm{Pi}$ is effective in studying the discipline and corresponds to the so-called deeper learning process. In work [51] the Raspberry Pi is proposed for training in the field of the Internet of things. Works [39, 40, 52] are dealing with the use of devices developed on the basis of this computer for training in the field of control through programming controllers. Work [40] describes the development of a platform consisting of an Arduino board and a Raspberry Pi with a REX system; work [39] also describes the use of other platforms in university education (Lego Mindstorm NXT, Arduino, Kinect); in work [52] there are described, inter alia, the possibilities of using the Python language for these purposes. In work [53] the results of using the Raspberry $\mathrm{Pi}$ in training in the field of pattern recognition are shown. In work [54] the possibility of using the Raspberry Pi in the teaching of electrical and computer engineering is considered. These disciplines are indeed among those for which it is difficult to organize full-fledged practical exercises in view of the requirement for the availability of certain hardware resources.

The described features of Raspberry Pi allow changing the operating system almost instantly on the computers; it is also a budget option to provide each student with several computers running on different operating systems. Such a solution will allow for the study of operating systems to clearly analyze and compare, make fine-tuning system settings (installing and uninstalling the system, working with the registry, manipulating disks and their partitions, working with boot record, low-level disk operations); in case of failure of the operating system or malfunction of its individual components and modes, recovery is not difficult, unlike the machines and networks that equip ordinary computer classes. "Computer Networks", in turn, is a discipline that acquires special practical significance in view of increasing the interconnectivity in the world and, accordingly, improving cyberattacks. Modern specialists in the field of information technologies, in particular, information security, need such skills and knowledge as network diagrams, their configuration, administration, working with peripheral devices for networking, security testing, access control in corporate networks, working with software firewalls. The technology presented in this work allows organizing precisely the individual performance of all these practical works.

Using the developed distributing sets of hardware and software components and Raspberry Pi microcomputers provides a way to an inexpensive solution to this problem: the calculations performed are presented in the paper. This implies providing 
each student individually with full-fledged equipment for studying operating systems and computer networks, which is perhaps the main condition for effective and deep acquisition of skills.

Studying the problems indicated above prompted the authors to the idea of commercializing the results of the described project to organize a universal mobile computer class. According to the general requirements of commercialization contests [5557], the result of scientific and technical activity is defined as a product, the market analysis has been performed (in Kazakhstan), and a technological plan has been developed. An initiative report on the existing reserve has been prepared.

\section{Methods}

The section provides the rationale for the work, highlights the aspect of solving the problem identified in the introduction, and describes in detail the process of its development and implementation.

\subsection{Studying and using software and hardware for teaching disciplines computer networks and operating systems"}

"Computer Networks" is a discipline that includes studying the theoretical and practical principles of using computer networks: organization and processes of data transfer between computers; connection of personal computers (PCs) to networks, work in them; use of hardware, software and information resources of networks; work with network applied programs.

A great role in the successful development of this field is played by the acquisition of practical skills. Modern specialists in the field of information technology, information security should know the network diagrams, work with the software firewall, have skills in configuring networks, should have good understanding of the principles of network administration, work with peripheral devices for networking, should be able to audit the existing security system, select, install and configure network technical facilities of information security.

When conducting classes in "ordinary" computer classes, it is generally not possible to provide real-time network setup, even for demonstration. The network is usually already configured and students are already working with the configured networks; for obvious reasons it is not practical to disassemble it. Or, what is increasingly observed, teaching and working is carried out through some platform-simulators.

The discipline "Operating Systems" includes studying the functions of operating systems, the composition and types of operating systems; principles of operation of various operating systems; principles of interaction of operating systems with peripheral devices and with the user; machine-dependent and machine-independent properties of operating systems. As a result, students should be able to use the means of operating systems and environments to ensure the operation of computer technology; install, configure and administer various operating systems [28]. 
Computers with two or three systems installed at the same time have to be rebooted to access a specific system and it is impossible to work simultaneously in both systems on the same workstation. The use of virtual machines is possible only if there is a large amount of RAM and a sufficiently powerful processor.

In view of the above reasons, as well as suitable technical specifications and the price of the Raspberry Pi microcomputer, it is advisable to use it as the alternative equipment and to organize a universal computer class based on it.

The analysis of the types and the required amount of equipment, as well as the development of an exemplary scenario for conducting classes, allowed developing, in the authors' opinion, the optimal basic distributing individual sets for each of the disciplines (Table 1). An expanded kit was also developed, including hardware and software components for performing various practical tasks on subjects. Note the possibility of completing additional network equipment such as transceivers, repeaters, hubs, bridges.

Table 1. The list of hardware and software components of distributing individual kits for the disciplines "Computer Networks" and "Operating Systems"

\begin{tabular}{|c|c|c|}
\hline \multicolumn{3}{|c|}{$\begin{array}{l}\text { Basic hardware-software structure of the handout individual kit in disciplines "Computer Net- } \\
\text { works" and "Operating Systems" } \\
\text { This package implies the presence of the required number of monitors (HDMI or VGA with the } \\
\text { appropriate adapter), USB-keyboards and USB-computer }\end{array}$} \\
\hline \multirow[t]{2}{*}{ Equipment name } & \multicolumn{2}{|c|}{\begin{tabular}{|c|} 
Discipline \\
\end{tabular}} \\
\hline & Computer networks & Operating systems \\
\hline Minicomputers Raspberry Pi 3B+ & $2-3$ pcs. & $2-3$ pcs. \\
\hline $\begin{array}{l}\text { Power adapter (s) (Raspberry Pi 3V+ power supply unit (s) } \\
\text { from a } 220 \text { V household network) }\end{array}$ & $2-3$ pcs. & $1-3$ pcs. \\
\hline $\begin{array}{l}\text { MicroSD with a pre-installed working environment for each } \\
\text { computer: OS, network and other necessary applications, } \\
\text { training materials (educational literature, guidelines for practi- } \\
\text { cal and laboratory exercises) }\end{array}$ & $2-3$ pcs. & $2-4$ pcs. \\
\hline Communication equipment & + & Not necessary \\
\hline \multicolumn{3}{|c|}{$\begin{array}{l}\text { Advanced structure of handout individual kits } \\
\text { The following equipment can be included in the minimum structure described above, which provides full } \\
\text { "computer class" mobility in terms of hardware }\end{array}$} \\
\hline \multicolumn{3}{|c|}{$\begin{array}{l}\text { Additional equipment: } \\
\text { - HDMI-displays with a small screen size (there are very budget options), } \\
\text { - mini USB or Bluetooth keyboard, } \\
\text { - USB mouse }\end{array}$} \\
\hline
\end{tabular}

Note. To conduct various classes in the discipline "Computer Networks", the training organization should have additional communication equipment. The name, the purpose and the required amount of equipment are given in Table 2. For a self-organized network, students can connect and configure the modem and the Internet in their computers (from their distribution kits). Further, having united in groups of 3-5 people, students can organize local subnets and, using intermediate local equipment, configure and connect their network to the common network and the Internet. 
Paper-Implementation and Commercialization of the Results of the "Multidisciplinary Mobile ..

Table 2. Equipment and recommendations for organizing additional practical classes in the discipline "Computer Networks"

\begin{tabular}{|l|l|l|}
\hline \multicolumn{1}{|c|}{ Equipment name } & \multicolumn{1}{|c|}{ Purpose } & \multicolumn{1}{c|}{ Amount and notes } \\
\hline Modem & $\begin{array}{l}\text { To access the global network (the } \\
\text { Internet) }\end{array}$ & 1 \\
\hline Router & $\begin{array}{l}\text { To combine subnets and central- } \\
\text { ized access to the Internet }\end{array}$ & 1 \\
\hline $\begin{array}{l}\text { Network switch, 5-port or 8-port } \\
\text { according to the number of hosts } \\
\text { in the subnet) }\end{array}$ & $\begin{array}{l}\text { To organize and configure local } \\
\text { subnets }\end{array}$ & $\begin{array}{l}\text { 3-5 for this amount you can form } \\
\text { subgroups of students with their own } \\
\text { subnet for additional practical tasks }\end{array}$ \\
\hline Network cables & $\begin{array}{l}\text { With corresponding equipment } \\
\text { specifications }\end{array}$ \\
\hline
\end{tabular}

\subsection{Determining the composition of kits for studying the disciplines "computer networks" and "operating systems"}

Table 1 shows the hardware and software options for individual training kits designed to study the disciplines "Computer Networks" and "Operating Systems" using the Raspberry Pi microcomputer.

Regarding the advanced structure of the kits, let's say that due to the Raspberry Pi having an HDMI interface, as well as the presence of HDMI-VGA and other similar adapters in the market, the entire set of monitors is available for this microcomputer (with the diagonal of displays from 2.2 inches to large enough screens, including touch screens, with various resolution variations, with various types of connection and response speed). In the project, a very low-budget compact monitor was used to create a trial prototype (Fig. 1). It is also clear that almost all types of keyboards and computer mice are applicable, including Bluetooth.
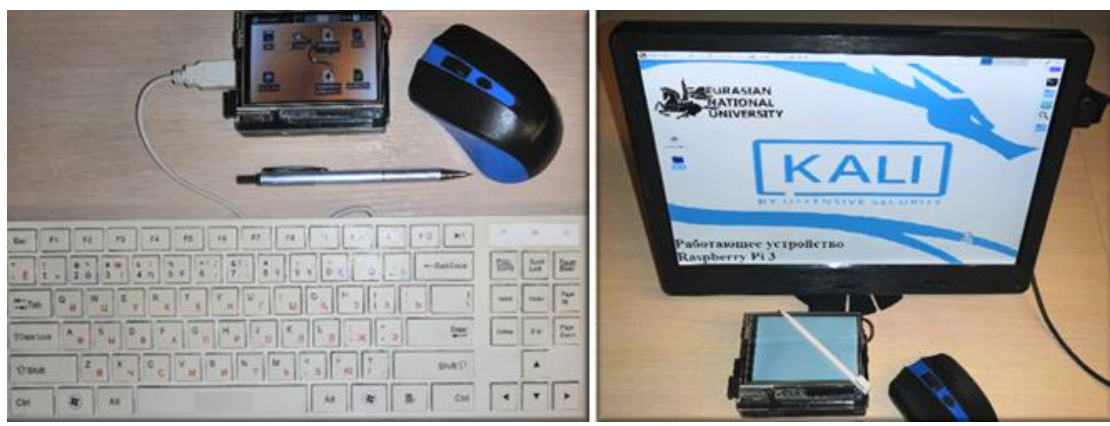

Fig. 1. Raspberry Pi with various displays

To conduct classes in these disciplines using the presented kits, there is needed a standard classroom (not a computer class!) with seats equipped with power points. Table 3 shows the part of the financial calculations made by the authors regarding the cost of the equipment that makes up the distribution kits, its dimensions and weight, excluding the intellectual component (microSD software, instructions, guidelines). 
Table 3. Approximate cost, sizes and weight of the equipment of a single individual handout kit

\begin{tabular}{|c|c|c|c|}
\hline No & Equipment name & Cost (US dollars) & $\begin{array}{c}\text { Sizes }(\mathrm{cm}) \text { and } \\
\text { weight }\end{array}$ \\
\hline 1 & $\begin{array}{l}\text { Case (depending on whether it is designed and manufac- } \\
\text { tured by the order, or is it adapted packaging of any mass- } \\
\text { produced goods) }\end{array}$ & $2.5-10$ & $\begin{array}{l}200 \times 250 \times 100 \\
0.2 \mathrm{~kg}\end{array}$ \\
\hline 2 & Minicomputers Raspberry Pi 3B + (2-3 pcs.) & $\begin{array}{l}35 \\
(2 \text { or } 3)\end{array}$ & $\begin{array}{l}85.6 \times 53.98 \times 17 \\
0.045 \mathrm{~kg} \\
(2 \text { or } 3)\end{array}$ \\
\hline 3 & $\begin{array}{l}\text { Power adapters (power supplies Raspberry Pi } 3 \mathrm{~V}+\text { from } \\
\text { the household network } 220 \mathrm{~V} \text { ) }\end{array}$ & $\begin{array}{l}4.5 \\
(2 \text { or } 3)\end{array}$ & $\begin{array}{l}8 \times 3 \times 4 \\
0.1 \mathrm{~kg} \\
(2 \text { or } 3)\end{array}$ \\
\hline 4 & Micro SD & $\begin{array}{l}15 \\
(2,3 \text { or } 4) \\
\end{array}$ & \\
\hline 5 & Mini USB Keyboard & 4.5 & $\begin{array}{l}20 \times 14 \times 1 \\
0.02 \mathrm{~kg}\end{array}$ \\
\hline 6 & USB mouse & 2.7 & $\begin{array}{l}10 \times 3.5 \times 6 \\
0.08 \mathrm{~kg} \\
\end{array}$ \\
\hline 7 & Network cables (Ethernet cable, $1 \mathrm{~Gb}$ ) & $\begin{array}{l}1 \\
(2 \text { or } 3)\end{array}$ & $0.05 \mathrm{~kg}$ \\
\hline 8 & (Digital-to-Analog HDMI-VGA Converter) & 3.5 & $\begin{array}{l}5 \times 5 \times 1.6 \\
0.04\end{array}$ \\
\hline & TOTAL: & $124.2-202.2$ & $0.68-0.825 \mathrm{~kg}$ \\
\hline
\end{tabular}

\subsection{Boot file and working environment}

Raspberry Pi minicomputers work from a boot disk to microSD (with the image of the operating system). You can boot from a USB-stick, as well as over the network. The mentioned in the work above microSD "with a pre-installed working environment" is a boot disk with a certain necessary OS configured and installed with the necessary software, recorded training material, customized working directory. The ability to download this working environment in the form of an archive is developed, after unpacking which immediately a working microSD is obtained. Using this archive, a boot file, saves users from searching for necessary OS images, using or even writing necessary scripts, searching and installing programs for creating boot disks, and fixing errors that often occur.

So, the composition of individual handout kits for studying the discipline "Operating Systems" can include three microSD with the operating systems Windows 10 IoT, FreeBSD, Ubuntu (boot files from Fedora, Ubuntu Server and Kali Linux are also available). Windows images already contain file managers, utilities for managing processes, services, and startup.

A script has been created that performs the following actions each time it starts:

- Launching the command line interpreter with convenient parameters and settings, including fonts for the correct display of the Russian and Kazakh languages (by default, the Windows command line is not configured for TrueType font that supports Unicode encoding) or, in the case of Unix/Linux, the terminal; 
- Necessary verification system commands (ip config / if config, etc.) with the output file;

- Transition to the working directory;

- Launching the file manager $(\mathrm{Far} / \mathrm{mc})$, some utilities.

To study the discipline "Computer Networks", handout kits are also equipped with microSD cards with various configured OS, pre-installed software (including Nmap, Wireshark, PuTTY, WinSCP) and training materials. A script has also been created that, in addition to the above actions, also performs the following:

- Launching some network application commands;

- Checking the network firewall settings.

\subsection{Instructions and guidelines}

A memo with a list of contents, a mock-up of instructions for completing kits and operating the Raspberry Pi and other equipment, as well as guidelines and recommendations for conducting classes in the relevant discipline using this kit and examples of tasks were developed.

The instruction includes information of the purpose of the equipment in the kits and the conditions for its effective and safe operation, characteristics and specifications of components, types and methods of safe connections.

The methodological guidelines describe the procedure for compiling and starting possible hardware configurations according to the studied disciplines (which can be done in the first practical (laboratory) class). An approximate list of practical tasks and guidelines for their implementation is also given. We note the possibility of modifying and developing new tasks. In particular, for the Computer Networks discipline, software tools and the possibilities of their use for setting up networks and shared directories, a firewall, etc. are described. Attention is paid to the issue of network security testing using Kali Linux distribution utilities.

Cases with kits are supposed to be numbered, equipped with a memo for completing depending on the type of discipline, and distributed in the classroom according to this information and numbers (additional terms of use are described in the attached guidelines).

\subsection{Commercialization issues}

The idea is based on the use of the Raspberry Pi microcomputer with specific software, including that specially designed for this project. The feasibility of implementing and commercializing this project is due to the advantages of this computer; together with the business research carried out, they are, moreover, the grounds for expecting its effectiveness and efficiency.

The degree of readiness of the project. Within the framework of this project, the following types of work were performed: 
- A review and analysis of single-board microcomputers of the same price category, with similar hardware capabilities, also supporting various assemblies and configurations;

- A preliminary analysis of the target market was completed;

- Considered technical issues of operation and durability of Raspberry Pi;

- The issues of designing as a commercial product the developed transfer kits and the technology of their use were investigated;

- Prototypes of hardware-software devices based on the Raspberry Pi were collected to study the disciplines of "Computer Networks", "Operating Systems":

- A boot file of the operating system with a customized working environment was developed;

- Documentation projects were developed: a memo of the content, operation and maintenance of this mobile computer class; instructions for using firmware in kits, connection methods and connections with the description of the characteristics of components;

- A part of the guidelines for the workshop in these disciplines was developed using the toolkits proposed in the project;

- Preliminary calculations of the cost of this production were made;

- Some business risks were highlighted, estimates of the return on production and implementation costs were given;

- Technological plan for the implementation of the subproject was developed;

- An initiative report on the existing backlog was prepared:

- Examples of using the projects and applications implemented on the basis of the Raspberry Pi are considered [58];

- An extensive review and analysis of sources on the Raspberry Pi was performed [59];

- The possibility of increasing productivity and expanding the scope of use of the microcomputer: components, peripherals, additional modules was considered;

- The ideas were described and research projects based on the Raspberry Pi 3 Model B and Raspberry Pi Zero models were partially implemented. A prototype of a hardware-software device was assembled and functions $[44,60]$;

- Within one of the projects, the device was partially implemented in the educational process in disciplines requiring an installed and configured complex of specific software (for example, cryptanalysis);

- In another project, the device was proposed to be used as a portable computer network security scanner.

Table 4 provides the information of the number of education institutions currently operating in the Republic of Kazakhstan and the student population according to open databases of official sources (data from the Statistics Committee [61]). 
Paper-Implementation and Commercialization of the Results of the "Multidisciplinary Mobile ...

Table 4. Education institutions at the beginning of 2019/2020 academic year in the Republic of Kazakhstan

\begin{tabular}{|c|l|c|c|}
\hline No & \multicolumn{1}{|c|}{ Education institution type } & $\begin{array}{c}\text { Number of } \\
\text { education institu- } \\
\text { tions }\end{array}$ & Number of students \\
\hline 1 & Comprehensive secondary schools & 7393 & 3186234 \\
\hline 2 & $\begin{array}{l}\text { Organizations of technical and vocational, post- } \\
\text { secondary education }\end{array}$ & 769 & 475443 \\
\hline 3 & $\begin{array}{l}\text { Higher education institutions with branches } \\
\text { Commercial education organizations of small and } \\
\text { medium-sized businesses, training centers }\end{array}$ & 119 & 604345 \\
\hline & Total: & 8405 & 1450 \\
\hline
\end{tabular}

Table 5 presents the list of potential users of the multidiscipline computer class based on Raspberry Pi.

Table 5. Target audience of the Multidiscipline computer class based on Raspberry Pi

\begin{tabular}{|l|l|}
\hline \multicolumn{1}{|c|}{ Potential users } & \multicolumn{1}{c|}{ Purposes of use } \\
\hline Higher education institutions & Teaching various disciplines, organization of circles \\
\hline $\begin{array}{l}\text { Secondary and secondary special educational } \\
\text { institutions }\end{array}$ & $\begin{array}{l}\text { Teaching various disciplines, conducting circles and } \\
\text { elective classes }\end{array}$ \\
\hline Research organizations & Research work \\
\hline Testing organizations & Knowledge cut \\
\hline $\begin{array}{l}\text { Commercial educational organizations, training } \\
\text { centers }\end{array}$ & $\begin{array}{l}\text { Organization and conducting courses in various } \\
\text { disciplines }\end{array}$ \\
\hline
\end{tabular}

In the course of studying and segmentation of the consumer market based on the analyzed statistical data (such as in Tables 4, 5 and others), the estimates of the actual number of consumers are obtained taking into account the influence of various factors.

The main stages of the project are highlighted and framed in the calendar plan, the necessary resources are calculated (financial, material and technical base). Table 6 describes the stages of the project. 
Table 6. Main stages of the project implementation

\begin{tabular}{|c|c|c|}
\hline $\begin{array}{l}\text { Stage } \\
\text { No. }\end{array}$ & Stage name & \begin{tabular}{|c|c|} 
Stage execu- \\
tion period
\end{tabular} \\
\hline 1 & Selection and acquisition of necessary hardware components & 3 mns. \\
\hline 2 & $\begin{array}{l}\text { Hardware and software assembly, debugging, optimization: } \\
\text { - assembly of devices and debugging of interfaces, displays and other peripheral } \\
\text { devices, as well as optimization; } \\
\text { - installation and debugging of different OS, as well as optimization of loading } \\
\text { and operation }\end{array}$ & 3 mns. \\
\hline 3 & $\begin{array}{l}\text { Refinement and testing of the working environment for the disciplines "Operating } \\
\text { Systems" and "Computer Networks" (Table 2): } \\
\text { - customized administration tools; } \\
\text { - utilities; } \\
\text { - specialized electronic library with recommended sources }\end{array}$ & $5 \mathrm{mns}$. \\
\hline 4 & $\begin{array}{l}\text { Creation in the form of archives of boot disks: } \\
\text { - development of necessary scripts; } \\
\text { - development of scripts for creating working microSD (automated launch of the } \\
\text { operating system with a customized working environment and regular work) and } \\
\text { testing; } \\
\text { - development of the possibility of using a boot disk in the form of an archive; } \\
\text { - documentation of the use of the boot disk and the implementation of online } \\
\text { support; } \\
\text { - record and configure the necessary environment created in clause } 3 \\
\end{array}$ & $5 \mathrm{mns}$. \\
\hline 5 & $\begin{array}{l}\text { Development of a methodological manual for the disciplines "Operating Sys- } \\
\text { tems" and "Computer networks" using this kit. }\end{array}$ & $4 \mathrm{mns}$. \\
\hline 6 & $\begin{array}{l}\text { Formation of individual handout training / work kits, creation and design of a } \\
\text { case for an individual handout set: } \\
\text { 1) case package design; } \\
\text { 2) documentation in } 3 \text { languages: } \\
\text { - description of the kit; } \\
\text { - user's manual; } \\
\text { - specifications; } \\
\text { 3) Hardware components depending on discipline (computers, external devices } \\
\text { and switching equipment, microSD, documentation) }\end{array}$ & 4 mns. \\
\hline 7 & Preparing and receiving patents & 4 mns. \\
\hline 8 & $\begin{array}{l}\text { Introduction into production and dissemination of the product in the Kazakhstan } \\
\text { market and abroad. } \\
\text { Advertising and marketing work: } \\
\text { - recruiting and training employees to distribute products; } \\
\text { - training, master classes, orientation seminars; } \\
\text { - organizing a video channel and online resource with support; } \\
\text { - advertising activity }\end{array}$ & $8 \mathrm{mns}$. \\
\hline
\end{tabular}

It should be noted that this project (commercialization) has not yet been launched but it is only proposed for implementation. The main condition of commercialization contests, which is a guaranteeing factor for successful implementation of projects: the involvement of business organizations as business partners in the stages of production and implementation of products (developed on the basis of previously obtained results of scientific and scientific-technical activities). In this, in essence the most important practical part of the project, at the moment only the algorithms and methods of identifying and attracting potentially interested business partners have been studied.

We note the need for a more detailed market analysis and revision, due to the relevance of the dates immediately before commercialization; practical detailing of fore- 
casts and calculations; presentation of the project in business terms; the development of methods and algorithms for attracting business partners and the corresponding regulatory package of documents.

\section{$3 \quad$ Results}

The results of this work can be divided into two types. The first one consists of the results obtained under the project "Multidisciplinary Mobile Computer Classroom Based on the Raspberry Pi". The list of constituent kits and developed recommendations for conducting classes, presented in Table 1, makes "Multidisciplinary Mobile Computer Classroom Based on the Raspberry Pi". In resource [16] there are presented some pictures for the project, including the case with the content of one of the handout kit: an industrial prototype. Table 7 describes a unit of the kit.

Table 7. A unit of the individual handout kit

\begin{tabular}{|l|}
\hline \multicolumn{1}{|c|}{ Case with a sticker on the outer surface with the necessary information and number } \\
\hline Content according to one of the options in Table 2 \\
\hline Content memo \\
\hline User's manual \\
\hline Guidelines for conducting classes in one of the disciplines using this kit and examples of tasks \\
\hline
\end{tabular}

The created archive (boot file) for each of the disciplines will be useful not only for teaching purposes, but generally for broad purposes, including for developers. The boot file, as well as the developed instructions that are a part of the presented distribution kits, are also available online [16]. The second type consists of the results obtained as a part of commercialization of the results of the first type. The project was not submitted for participation in the commercialization competition for the reasons indicated in section II.5. Nevertheless, at the moment, a lot of the fundamental laborious work at preparing for the project commercialization presented in sections II.1-II.4 of this article has been completed. The market analysis, a technological plan, a risk assessment, a forecast of efficiency, with the reference mainly to Kazakhstan, were carried out. The result of scientific and technical activities proposed for commercialization is highlighted. The developed prototype of "Multidisciplinary Mobile Computer Classroom Based on the Raspberry Pi Microcomputer" is a set of software and hardware tools for studying the disciplines "Computer Networks" and "Operating Systems". For commercialization, we offer kits of software and hardware equipment with relevant documentation for studying the disciplines "Operating Systems" and "Computer Networks", as well as the developed methodological manual for conducting disciplines using these kits.

\section{Discussion}

Study of the discipline "Computer networks" using Raspberry Pi microcomputers will provide every student with everything needed for developing, administering net- 
works and performing specific tasks. As it has already been noted, these microcomputers have a built-in network card. Students will be able to acquire such skills and knowledge as networking schemes, network administration and network configuration; work with software firewalls and peripheral devices for networking; security testing; selection, installation, configuration and maintenance of technical tools for information security.

Using this handout kit in the "Operating Systems" discipline, you can quickly "install" (simply by inserting the desired MicroSD card) the desired operating system, "reinstall", change the OS; work with different operating systems simultaneously on different devices individually; manipulate disks and their partitions; perform system settings, install device drivers and software diagnose the OS. These and other possible operations can, in fact, be unsafe for stationary PCs with the traditionally installed operating system in the sense of risk of disrupting the regular operation of the system and bootloader. Using the Raspberry Pi to "install" and "reboot" the OS, it is enough to simply replace the MicroSD card with another one from the kit or download a copy of the boot disk to the MicroSD from the support site. Note that the boot disk is made in the form of an archive, that is, it does not require the use of any additional software that is usually used to create boot disks from image files.

Thus, the use of the developed distribution kits will provide each student with machines in terms of the number of OSs studied, as well as in the amount sufficient to build and configure networks of various topologies. The paper defines the form factor and weight of the distribution kits. The kits do not require storage in specially equipped rooms, their transfer is not time-consuming due to their small size and weight, in connection with which we note the legitimacy of using the word "mobile" in the name of the work and project. This technology of using kits and guidelines for their use in teaching makes it possible to provide each student with the necessary equipment and support for acquiring practical skills, which is especially problematic because of the reasons already mentioned in Section I for precisely such disciplines.

These specific technical difficulties prompted us to offer the technology primarily for teaching the disciplines "Computer Networks" and "Operating Systems", as well as for commercialization. The authors are faced with the task of going through the formal procedure of introducing the kits of Raspberry Pi, developed as a part of the project presented in the work, into the educational process at the university.

It was already noted that for the same reasons, Raspberry Pi was proposed in work [41] to teach $\mathrm{C} / \mathrm{C}++$ and Java programming languages. We add that the performance of Raspberry Pi (for example, Model 3B) allows writing and debugging Python programs with a graphical interface using the PyQt library without any visible delays in operation (see [58], [30-33]). This means that the necessary tools for programming in bash [60, 15], C/C++, Fortran, Python, Java and other languages in Raspberry Pi are available, and the level of performance for teaching programming is sufficient. Works $[43,45]$ describe the use of the Raspberry Pi in the teaching of certain disciplines; for example, [45] refers to the experience of teaching in the field of information security. So, the authors of this work successfully used a device based on Raspberry Pi, for example, at a workshop on cryptography and cryptanalysis, which requires preinstalled specialized software (compilers, libraries, software implementations, etc.) 
(see [44]). Note that projects similar to [45, 46], [54] are described in [44]. Like [46], in works $[15,16]$ a step-by-step description of the assembly in the headless-mode of a mobile device with a display, installation and configuration of software is also given; relevant practical recommendations are given, too. For this, the authors created a myservice script (available at link [16]) that must be placed in the /etc/init.d directory and made executable, then created a symbolic link to this script in the /etc/rc2.d directory. We note here that the most useful and effective recommendations and an example of setting up TFT displays for Raspberry Pi with the Raspbian operating system are given in work [62]. However, it does not provide solutions for a lot of problems that arise when setting up the screen; for example, to provide faster downloads. The destination of static IP can be found in the section "Setting a Static IP" of resource [63]; note, however, that static IP increases the system boot time by about 2 minutes. Finally, we note a very useful section "By The Way: Modifying Headless Raspberry Pi Boot Sequence" of resource [63] for solving problems with running ssh. However, it is worth noting that in [46] the work was performed for a whole cluster, and not for a single computer, as in works $[15,16]$.

The paper describes in detail the developments based on the Raspberry Pi for teaching two disciplines in terms of organizing effective workshops. In this connection, such an important component of these microcomputers the popularity was practically not considered as continuously appearing additional modules, hardware interfaces and their specifications $[28,36,37,64,65]$, which make it a convenient and flexible tool in implementing various projects.

The developments proposed in the project are new in that the kit for studying the discipline "Operating Systems" provides an alternative way that allows changing the operating system almost instantly on computers; it is also a budget option to provide each student with several computers running on different operating systems. The developed individual distribution kit for studying the discipline "Computer Networks" allows providing each student with everything needed to acquire practical skills: creating, administering networks, and performing specific tasks. The authors also developed and implemented a part of the software package to optimize the use of the Raspberry Pi for the designated purposes. The authors developed a part of the software package for optimizing the use of the Raspberry Pi for the designated purposes, developed a commercial product and related documentation. Finally, Kazakhstan has not commercialized results in this area.

\section{Conclusion}

According to the results of the studies carried out at this point, it can be argued that the idea and the completed developments demonstrate objective possibilities of their application for the indicated purposes, while business risks are predictable, controllable, and preventive measures are applicable to many of them. From the point of view of the effectiveness of training using the proposed kit and methodological guidelines, one should expect a high degree of assimilation and acquisition of sustainable skills due to the deep degree of involvement, the presence of really practical exercises, and 
the "freedom" to experiment without risking significant harm to hardware and software. Taking into account the budget of this training kit, which also does not require special permanent premises and storage conditions, we consider this project a good opportunity to provide all students with practical tools, which in a significant degree, if not completely, covers potential disadvantages. In addition, we note the practical usefulness of all the hardware and software components per se, significant operating periods, and the presence of many areas of their application.

\section{References}

[1] Stanford (2020). Mitchell A65 Computer Teaching Lab. Stanford University. Available: https://pangea.stanford.edu/r25/ma65/calendar[Accessed: May 07, 2020].

[2] Stanford (2020). Computers. Mitchell A-65 Computer Teaching Lab, Computers. Available: https://a65lab.stanford.edu/equipment/computers[Accessed: May 07, 2020].

[3] Stanford (2020). The 24-hour study room. Stanford libraries. Available: https://library.stanford.edu/libraries/lathrop/24-hour-study-room [Accessed: May 07, 2020].

[4] Electrical Engineering \& Computer Science (2019). 6.S083 Introduction to Computational Thinking. Available: https://www.eecs.mit.edu/academics-admissions/academicinformation/subject-updates-fall-2019/6s083 [Accessed: May 07, 2020].

[5] Harvard University (2019). Research Technology. Accelerating research from the Desktop to the Teraflop. Available: https://cls.iq.harvard.edu/[Accessed: May 07, 2020].

[6] Carnegie Mellon University (2020). Classroom and Computer Lab Locations. Available: https://www.cmu.edu/computing/services/teach-learn/tes/locations.html[Accessed: May 07, 2020].

[7] Garnegie Mellon University (2020). Computing Services, Morewood Gardens (MOR). Available:https://www.cmu.edu/computing/services/teach-learn/tes/computerlabs/locations/morewood-labs.html [Accessed: May 06, 2020].

[8] Garnegie Mellon University (2020). Computing Services, Residence on Fifth (ROF). Available:https://www.cmu.edu/computing/services/teach-learn/tes/computerlabs/locations/residence-fifth-labs.html [Accessed: May 06, 2020].

[9] Garnegie Mellon University (2020). Computing Services, Cyert Hall (CH). Available:https://www.cmu.edu/computing/services/teach-learn/tes/computerlabs/locations/cyert-labs.htmlтолько mac [Accessed: May 06, 2020].

[10] Garnegie Mellon University (2020). Computing Services. Hunt Library (HL). Available: https://www.cmu.edu/computing/services/teach-learn/tes/computer-labs/locations/huntlabs.html только Windows [Accessed: May 06, 2020].

[11] Ryane, I. (2020). A case study of using Edmodo to enhance computer science learning for engineering students. International Journal of Emerging Technologies in Learning, 15(3): 62-73. https://doi.org/10.3991/ijet.v15i03.11252

[12] Garmpis, A., Gouvatsos, N. (2012). Innovative teaching methods in operating systems: The Linux case, 1: 155-163.

[13] Yang, J., Lee, T.Y., Chen, B., Zhang, W. (2019). A Comprehensive Teaching Reform Model for a Computer Networks Course Based on Integrated Information Systems. International Journal of Emerging Technologies in Learning, 14(18): 76-91. https://doi.org/10. $\underline{3991 / i j e t . v 14 i 18.11040}$ 
[14] Akhmetshin, E.M., Mueller, J.E., Yumashev, A.V., Kozachek, A.V., Prikhodko, A.N., Safonova, E.E. (2019). Acquisition of entrepreneurial skills and competences: Curriculum development and evaluation for higher education. Journal of Entrepreneurship Education, 22(1): 1-12.

[15] Ospanova, A.B., Sagindykov, K.M., Tuleuov, B.I., Zharkimbekova, A.T. (2018). Raspberry $\mathrm{Pi}(3$ model B) microcomputer and practical prospects for its use. In VII International Scientific-Technical and Scientific-Methodological Conference. Collection of scientific articles in 4 volumes, edited by S.V. Bachevsky. St. Petersburg: St. Petersburg State University of Telecommunications, pp. 324-329.

[16] Eurasian National University (2010). Available: http://www.enu.kz/en/ [Accessed: May 06, 2020].

[17] Saffran, J., Garcia, G., Souza, M.A., Penna, P.H., Castro, M., Góes, L.F., Freitas, H.C. (2016). A low-cost energy-efficient Raspberry Pi cluster for data mining algorithms. In European Conference on Parallel Processing. Springer, Cham, pp. 788-799. https://doi.org/ $\underline{10.1007 / 978-3-319-58943-5 \_63}$

[18] Rodríguez, R.A., Cammarano, P., Giulianelli, D.A., Vera, P.M., Trigueros, A., Albornoz, L.J. (2018). Using Raspberry Pi to Create a Solution for Accessing Educative Questionnaires From Mobile Devices. IEEE Revista Iberoamericana de Tecnologias del Aprendizaje, 13(4): 144-151. https://doi.org/10.1109/rita.2018.2879387

[19] Da Fontoura Haeser, E., Miletto, E.M. (2017). Development of the Gambiarrádio educational prototype: Device for transmitting audio via FM radio waves based on Raspberry Pi. In 2017 International Symposium on Computers in Education (SIIE). IEEE, pp. 1-6. https ://doi.org/10.1109/siie.2017.8259675

[20] Bermudez-Ortega, J., Besada-Portas, E., Lopez-Orozco, J.A., Bonache-Seco, J.A., De la Cruz, J.M. (2015). Remote Web-based Control Laboratory for Mobile Devices based on EJsS, Raspberry Pi and Node.js. IFAC-Papers OnLine, 48(29): 158-163. https://doi.org/10. 1016/j.ifacol.2015.11.230

[21] Ferdoush, Sh., Li, X. (2014). Wireless Sensor Network System Design using Raspberry Pi and Arduino for Environmental Monitoring Applications. In The 9th International Conference on Future Networks and Communications (FNC-2014). Procedia Computer Science, 34: 103-110. https://doi.org/10.1016/j.procs.2014.07.059

[22] Schlobohm, J., Pösch, A., Reithmeier, E. (2016). A Raspberry Pi Based Portable Endoscopic 3D Measurement System. Electronics, 5(43): 56-62. https://doi.org/10.3390/electro nics5030043

[23] Bates, D. (2015). Raspberry Pi Projects for Kids. 2nd ed. Birmingham-Mumbai, Packt.

[24] Quinlan, O., Baloro, S. (2018). Raspberry Pi computers in schools. Raspberry Pi Foundation Research No. 5.

[25] Schwartz, M. (2016). Building Smart Homes with Raspberry Pi Zero. BirminghamMumbai, Packt.

[26] Petin, V.A. (2016). Arduino and Raspberry Pi in Intemet of Things Projects. St. Petersburg: BHV-Peterburg.

[27] Chin, S., Weaver, J. (2016). Raspberry Pi with Java. Programming the Internet of Things (IoT) Birmingham-Mumbai, Packt.

[28] Soper, M.E. (2017). Expanding Your Raspberry Pi: Storage, printing, peripherals, and network connections for your Raspberry Pi. Indianapolis (Indiana, USA), Apress. https:// doi.org/10.1007/978-1-4842-2922-4_10

[29] Tzivaras, V. (2017). Raspberry Pi Zero W Wireless Projects. Birmingham-Mumbai, Packt Publishing.

[30] Norbom, H. (2017). Raspberry Pi Python Projects. Python3 and Tkinter. 
[31] Kelly, S. (2016). Python, PyGame and Raspberry Pi Game Development. Niagara Falls, Ontario, Canada: Apress. https://doi.org/10.1007/978-1-4842-2517-2 20

[32] Yamanoor, S., Yamanoor, S. (2017). Python programming with Raspberry Pi Zero. Build small yet powerful robots and automation systems with Raspberry Pi Zero. BirminghamMumbai: Packt. https://doi.org/10.1109/ghtc.2017.8239274

[33] Donat, W. (2014). Learn Raspberry Pi Programming with Python. Niagara Falls, Ontario, Canada: Apress.

[34] Shah, S. (2015). Learning RaspberryPi. Birmingham-Mumbai: Packt.

[35] Cyberpunk University (2016). Python: The No-Nonsense Guide. Cyberpunk University.

[36] Monk, S. (2016). Cookbook by Raspberry Pi. United States of America: O’Reilly.

[37] Gay, W. (2017). Custom Raspberry Pi Interfaces: Design and build hardware interfaces for the Raspberry Pi. St Catharines, Ontario, Canada: Apress. https://doi.org/10.1007/978-14842-2406-9_12

[38] Admin (2016). Raspberry Pi Analogs. Available: https://losst.ru/luchshie-analogi-raspbe rry-pi [Accessed: January 31, 2020].

[39] Irigoyen, E., Larzabal, E., Priego, R. (2013). Low-cost platforms used in Control Education: An educational case study. In 10th IFAC Symposium Advances in Control Education. The Int. Federation of Automatic Control (August 28-30). Sheffield, UK, pp. 256-261. https://doi.org/10.3182/20130828-3-uk-2039.00058

[40] Sobota, Ja., Pisl, R., Balda, P., Schlegel, M. (2013). Raspberry Pi and Arduino boards in control education. In 10th IFAC Symposium Advances in Control Education. The International Federation of Automatic Control (August 28-30). Sheffield, UK, pp. 262-269. https ://doi.org/10.3182/20130828-3-uk-2039.00003

[41] David, S.A., Ravikumar, S., Parveen, A.R. (2018). Raspberry Pi in Computer Science and Engineering Education. In Intelligent Embedded Systems. Springer, Singapore, pp. 11-16. https://doi.org/10.1007/978-981-10-8575-8_2

[42] Official site of Raspberry Pi. Available: https://www.raspberrypi.org/ [Accessed: January 31, 2020].

[43] Adams, J.C., Brown, R.A., Kawash, J., Matthews, S.J., Shoop, E. (2018). Leveraging the Raspberry Pi for CS Education. In Proceedings of the 49th ACM Technical Symposium on Computer Science Education, pp. 814-815. https://doi.org/10.1145/3159450.3159611

[44] Ospanova, A.B., Tuleuov, B.I. (2018). Prospects for the use of the Raspberry Pi microcomputer in the effective digitalization of Kazakhstan. Bulletin of the Eurasian National University named after L.N. Gumilyov. Mathematics Series. Computer science. Mechanics, 4(125): 95-107. https://doi.org/10.32523/2616-7182-2018-125-4-95-107

[45] Emani, R., Glantz, E.J., Gamrat, C., Hills, M.K. (2019). Using the Raspberry Pi in IT Education. In Proceedings of the 20th Annual SIG Conference on Information Technology Education, pp. 153-153. https://doi.org/10.1145/3349266.3351373

[46] Doucet, K., Zhang, J. (2019). The Creation of a Low-cost Raspberry Pi Cluster for Teaching. In Proceedings of the Western Canadian Conference on Computing Education, pp. 15. https://doi.org/10.1145/3314994.3325088

[47] Matthews, S.J., Adams, J.C., Brown, R.A., Shoop, E. (2018). Portable parallel computing with the raspberry pi. In Proceedings of the 49th ACM Technical Symposium on Computer Science Education, pp. 92-97. https://doi.org/10.1145/3159450.3159558

[48] Cox, S.J. (2012). Steps to make Raspberry Pi Supercomputer. University of Southampton. Available: http://www.southampton.ac.uk/ sjc/raspberrypi/pi_supercomputer_southamp ton_web.pdf [Accessed: January 31, 2020]. 
[49] Cox, S.J., Cox, J.T., Boardman, R.P., Johnston, S.J., Scott, M., O’brien, N.S. (2014). Iridis-pi: a low-cost, compact demonstration cluster. Cluster Computing, 17(2): 349-358. https://doi.org/10.1007/s10586-013-0282-7

[50] ElAarag, H. (2017). Deeper learning in computer science education using raspberry Pi. Journal of Computing Sciences in Colleges, 33(2): 161-170.

[51] Mahmood, S., Palaniappan, S., Hasan, R., Sarker, K. U., Abass, A., Rajegowda, P. M. (2019). Raspberry PI and role of IoT in Education. In 2019 4th MEC International Conference on Big Data And Smart City. IEEE, pp. 1-6. https://doi.org/10.1109/icbdsc.2019.8645 $\underline{598}$

[52] Hoyo, A., Guzman, J.L., Moreno, J.C., Berenguel, M. (2015). Teaching Control Engineering Concepts using Open Source tools on a Raspberry Pi board. IFAC-Papers OnLine, 48(29): 99-104. https://doi.org/10.1016/j.ifacol.2015.11.220

[53] Marot, J., Bourennane, S. (2017). Raspberry Pi for image processing education. In 2017 25th European Signal Processing Conference. IEEE, pp. 2364-2366. https://doi.org/10.23 919/eusipco.2017.8081633

[54] Hajjar, S., Spears, T. (2019). Hardware Microprogramming Education Using Raspberry PI and Arduino Technologies. International Journal of Intelligent Information Systems, 8(2): 47-51. https://doi.org/10.11648/j.ijiis.20190802.12

[55] Minister for Investment and Development of the Republic of Kazakhstan (2015). On approval of the rules for the provision of innovative grants for the commercialization of technologies. Available: https://egov.kz/cms/ru/law/list/V1500012067 [Accessed: January 06, 2020].

[56] RNTD Commercialization. Available: http://sc.edu.gov.kz/main/commercialization-of-r-d/ [Accessed: January 06, 2020].

[57] JSC «Science Fund». Available: http://science-fund.kz/konkursy/normativnyie-akty [Accessed: January 06, 2020].

[58] Sagindykov, K.M., Ospanova, A.B., Zharkimbekova, A.T. (2019). Opportunity of using projects and applications developed on the basis of Raspberry Pi microcomputer. Bulletin of the Almaty University of Energy and Communications. Series Information Technology, 1(44): 80-85.

[59] Sagindykov, K.M., Ospanova, A.B., Zharkimbekova, A.T. (2019). Analysis of sources related to Raspberry Pi microcomputer. Bulletin of Shakarim Semey State University. Series Engineering, 3(87): 79-84.

[60] Ospanova, A.B., Sauanov, B. (2017). Network Security Tools Based on Raspberry Pi. In The 4th International Scientific and Practical Conference "Intellectual information and communication technologies as tools for realization of the third industrial revolution devoted for the strategy Kazakhstan-2050", Astana, pp. 380-382.

[61] Official website of the Committee on Statistics of the Republic of Kazakhstan. Available: http://stat.gov.kz/official/industry/62/statistic/7 [Accessed: January 06, 2020].

[62] Re4son (2018). Latest Kali Linux on Raspberry Pi with Touch Screen, Bluetooth and touch optimised interface (New: Bluetooth, Rogue AP, Remote access AP, more tools). Available: https://whitedome.com.au/re4son/kali-pi/[Accessed: January 10, 2020].

[63] Kali Raspberry Pi/Headless Available: https://charlesreid1.com/wiki /Kali_RaspberryPi/Headless [Accessed: January 11, 2020].

[64] Raspberry Pi Expansion Boards. Available: https://geektimes.ru/post/285156/ [Accessed: January 10, 2020].

[65] Pinout and description of Raspberry Pi GPIO sockets (model B and B+). Available: http://raspberrypi.ru/gpio_pinout_pi3/[Accessed: January 11, 2020]. 


\section{Authors}

Zharkimbekova Aizhan Temirzhanovna is a doctoral student of the Computer Science and Information Security Department, L.N. Gumilyov Eurasian National University, Nur-Sultan, Kazakhstan.

Ospanova Ademi Bekzhanovna - Candidate of Physico-Mathematical Sciences, Assistant Professor of the Computer Science and Information Security Department, L.N. Gumilyov Eurasian National University, Nur-Sultan, Kazakhstan.

Sagindykov Kakim Moldabekovich - Candidate of Technical Sciences, Associate Professor, Head of the Department of Informatics and Information Security, L.N. Gumilyov Eurasian National University, Nur-Sultan, Kazakhstan.

Kokkoz Makhabbat Meyramkizi - Candidate of Pedagogical Sciences, Head of Department of Information Technology and Security, Karaganda State Technical University, Karaganda, Kazakhstan.

Article submitted 2020-04-21. Resubmitted 2020-05-26. Final acceptance 2020-05-28. Final version published as submitted by the authors. 